\title{
Primary Biliary Cirrhosis: Bad Genes, Bad Luck
}

\author{
Pietro Invernizzi • M. Eric Gershwin
}

Published online: 14 January 2012

(C) Springer Science+Business Media, LLC 2012

Primary biliary cirrhosis (PBC) is considered a model for autoimmune disease based upon its hallmark autoantibodies serologic response, the focused target destruction of biliary epithelial cells (BEC), and the clinical homogeneity among patients [1]. PBC is also overwhelmingly a disease of middle-aged and older females, being virtually absent in the pediatric or adolescent population. True pediatric PBC is indeed highly rare, and likely represents an etiopathogenesis that is extremely atypical compared to the classical PBC in adults. PBC also has one of the latest ages of onset out of all autoimmune diseases [2]. The etiology remains enigmatic, although various genetic and environmental factors have been implicated in the disease development and progression, many of which also provide insight as to why females are more prone to $\mathrm{PBC}[3,4]$.

Both genetic and environmental factors may well contribute to the decline of an already ageing immune system, a phenomenon termed immunosenescence [5], through recurrent infections and inflammation, as well as oxidative damage. Immunosenescence is known to begin in approximately the fifth decade of life, and is characterized by a progressive decline in immunological functioning [5-8]. It is likely that the immune system may then reach a critical stage where tolerance to self is lost, thus contributing to the development of autoimmune diseases. A number of studies showing immunosenescence have provided additional

P. Invernizzi

Center for Autoimmune Liver Diseases,

IRCCS Istituto Clinico Humanitas, Rozzano, Italy

P. Invernizzi · M. E. Gershwin ( $\square)$

Division of Rheumatology, Allergy and Clinical Immunology,

University of California, 451 E. Health Science Drive, Davis,

CA 95616, USA

e-mail: megershwin@ucdavis.edu evidence as to why middle age presentation often occurs in PBC. For example, changes in T cell signaling such as the decreased expression of the co-stimulatory receptor CD28, have been largely described [7, 11]. In PBC, an age-related progressive increase number of immune-related circulating cells carrying only one $\mathrm{X}$ chromosome, that is with monosomy X, was reported $[9,10]$. Again, several phenotypical and functional changes have been also noted in the CD4 and CD8 T lymphocytes of PBC patients [1]. Of interest is for example the increased CD127 (marker of effector cells), reduced CD39 (marker of normal Treg function) expression of the CD8 Treg, and that CD8+CD28-cells from PBC patients failed to display a regulatory immune response after incubation with IL-10 [12].

A growing number of evidences suggest that not only immunosenescence but also senescence of the target organ, that is of BEC, has a role in the development of PBC. Senescence is a well-known delayed stress response induced by factors such as oxidative stress, telomere shortening, DNA damage, and autophagy [13]. First, several studies have demonstrated that oxidative stress is an inducer of cell senescence in the BEC of PBC patients [1416]. Sasaki et al. [14] notes that cellular senescence in early-stage PBC was associated with an infiltration of myeloperoxidase-positive inflammatory cells, indicating oxidative stress. Another study by the same group showed that Bmil (a suppressor of oxidative stress) was significantly reduced in damaged BEC of PBC patients [16]. Second, shortened telomere length with associated cellular senescence has been demonstrated in a study by Sasaki and colleagues [17]. In particular, they examined telomere length using quantitative fluorescent in situ hybridization of 13 patients with PBC and 13 controls and showed a significant decrease in telomere length in damaged $\mathrm{BEC}$ from $\mathrm{PBC}$ patients, in comparison to histologically normal 
BEC in PBC patients and controls [17]. They also performed immunohistochemical studies for senescence markers $\mathrm{p} 16^{\mathrm{INK} 4 \mathrm{a}}$ and $\mathrm{p} 21^{\mathrm{WAF} / \mathrm{Cip} 1}$, and DNA damage, and demonstrated that telomere shortening is associated with DNA damage and cellular senescence as a feature of damaged BEC in PBC [17]. Third, senescent BEC seem to promote an environment that is pro-inflammatory and profibrotic through secretion of chemokines (IL-8 and MCP-1) and cytokines (such as IL-1 and IL-6) [18-22]. Fourth and final, autophagy, a self-degradative process known to be involved in the maintenance of senescence, may provide a route for BEC damage and possibly for exposure of autoantigens into a previously established inflammatory environment [21, 23, 24]. Autophagy is a process where intracellular proteins and organelles are degraded to suppress damage and maintain metabolism of senescent cells $[25,26]$. In PBC, autophagy was associated with senescence in a recent study by Sasaki and colleagues in which liver samples from $37 \mathrm{PBC}$ and 75 controls were stained for autophagy markers LC3, cathepsin-D, and LAMP-1, as well as for senescence markers $\mathrm{p} 16^{\mathrm{INK} 4 \mathrm{a}}$ and $\mathrm{p} 21^{\mathrm{WAF} / \mathrm{Cip} 1}$ [24]. Indeed, they showed that LC3 was expressed in about $90 \%$ of inflamed and only one-third of non-inflamed BEC of patients with $\mathrm{PBC}$, and co-localized with cathepsin-D, LAMP-1, p16 $6^{\mathrm{INK} 4 \mathrm{a}}$ and $\mathrm{p} 21^{\mathrm{WAF} / \mathrm{Cip} 1}$ [24]. They also showed that oxidative stress (induced by hydrogen peroxide), DNA damage (induced by Etoposide), and serum deprivation, cause BEC senescence in vitro. Finally, they showed that stress induced by senescence was reduced by inhibiting autophagy, including a reduction of senescence associated phenotype markers CCL2 and CX3CL1 [24].

In the current issue of Digestive Diseases and Sciences, Sasaki and colleagues [27] not only confirm their previous findings that autophagy is strongly linked to BEC senescence in PBC [24], but clearly demonstrate that autophagy precede cellular senescence of BEC. The major strength of this study is the staining of this large collection of liver tissues from patients with $\mathrm{PBC}$ and controls. In particular, they evaluated PBC cases with both early and advanced liver diseases, thus allowing the identification of autophagy (LC3), autophagyrelated (p62), and senescence (p16 $\left.6^{\mathrm{INK} 4 \mathrm{a}}, \mathrm{p} 21^{\mathrm{WAF} 1 / \mathrm{Cip} 1}\right)$ markers at different stages of the disease, and so obtaining information on the temporal occurrence and relationship of these processes. However, confirmatory studies using even larger cohort, as well as contemporary analysis of apoptosis in the BEC of PBC patients is warranted. Indeed, although senescence and autophagy may play a role in BEC damage and autoantigen exposure, the competitive process of apoptosis has also been studied in PBC [28-31].

In conclusion, current evidence surrounding the ageing immune system and the aging of target organ may well explain the increased risk of developing PBC in later life. We submit that our understanding of the underling pathogenic mechanisms of $\mathrm{PBC}$ will have to go through the consideration of senescence (both immunosenescence and senescence of the target organ). Accordingly, we believe that is time to perform an ambitious and integrated study, which will contemporarily consider all the key processes till now suggest to have a role in PBC development and progression. Obviously, such study should be based on state-of the art approaches, such as tissue-arrays, geneticproteomic approaches, etc., evaluate both immune-related cells and BEC, and involved a very large and well-defined case and control series; Strong expertise in immunology and molecular and cellular biology should be involved in this effort.

Conflict of interest No conflicts of interest exist.

\section{References}

1. Invernizzi P, Selmi C, Gershwin ME. Update on primary biliary cirrhosis. Dig Liver Dis. 2010;42:401-408.

2. Invernizzi P. Geoepidemiology of autoimmune liver diseases. J Autoimmunol. 2010;34:J300-J306.

3. Invernizzi P, Pasini S, Selmi C, Gershwin ME, Podda M. Female predominance and $\mathrm{X}$ chromosome defects in autoimmune diseases. J Autoimmunol. 2009;33:12-16.

4. Hirschfield GM, Invernizzi P. Progress in the genetics of primary biliary cirrhosis. Semin Liver Dis. 2011;31:147-156.

5. Hakim FT, Flomerfelt FA, Boyiadzis M, Gress RE. Aging, immunity and cancer. Curr Opin Immunol. 2004;16:151-156.

6. Prelog M. Aging of the immune system: a risk factor for autoimmunity? Autoimmunol Rev. 2006;5:136-139.

7. Weng NP, Akbar AN, Goronzy J. Cd28(-) t cells: their role in the age-associated decline of immune function. Trends Immunol. 2009;30:306-312.

8. Vallejo AN. Immunological hurdles of ageing: indispensable research of the human model. Ageing Res Rev. 2011.

9. Invernizzi P, Miozzo M, Battezzati PM, et al. Frequency of monosomy $\mathrm{x}$ in women with primary biliary cirrhosis. Lancet. 2004;363:533-535.

10. Miozzo M, Selmi C, Gentilin B, et al. Preferential $\times$ chromosome loss but random inactivation characterize primary biliary cirrhosis. Hepatology. 2007;46:456-462.

11. Vallejo AN. Cd28 extinction in human t cells: altered functions and the program of t-cell senescence. Immunol Rev. 2005;205: $158-169$

12. Bernuzzi F, Fenoglio D, Battaglia F, et al. Phenotypical and functional alterations of $\mathrm{cd} 8$ regulatory $\mathrm{t}$ cells in primary biliary cirrhosis. J Autoimmunol. 2010;35:176-180.

13. Collado M, Blasco MA, Serrano M. Cellular senescence in cancer and aging. Cell. 2007;130:223-233.

14. Sasaki M, Ikeda H, Haga H, Manabe T, Nakanuma Y. Frequent cellular senescence in small bile ducts in primary biliary cirrhosis: a possible role in bile duct loss. J Pathol. 2005;205:451-459.

15. Sasaki M, Ikeda $\mathrm{H}$, Nakanuma Y. Activation of atm signaling pathway is involved in oxidative stress-induced expression of mito-inhibitory p21waf1/cip1 in chronic non-suppurative destructive cholangitis in primary biliary cirrhosis: an immunohistochemical study. J Autoimmunol. 2008;31:73-78.

16. Sasaki M, Ikeda H, Sato Y, Nakanuma Y. Decreased expression of bmi1 is closely associated with cellular senescence in small 
bile ducts in primary biliary cirrhosis. Am $J$ Pathol. 2006;169:831-845.

17. Sasaki M, Ikeda H, Yamaguchi J, Nakada S, Nakanuma Y. Telomere shortening in the damaged small bile ducts in primary biliary cirrhosis reflects ongoing cellular senescence. Hepatology. 2008;48:186-195.

18. Shimoda S, Harada K, Niiro H, et al. Biliary epithelial cells and primary biliary cirrhosis: the role of liver-infiltrating mononuclear cells. Hepatology. 2008;47:958-965.

19. Alvaro D, Mancino MG, Glaser S, et al. Proliferating cholangiocytes: a neuroendocrine compartment in the diseased liver. Gastroenterology. 2007;132:415-431.

20. Isse K, Harada K, Zen $\mathrm{Y}$, et al. Fractalkine and $\mathrm{cx} 3 \mathrm{cr} 1$ are involved in the recruitment of intraepithelial lymphocytes of intrahepatic bile ducts. Hepatology. 2005;41:506-516.

21. Sasaki M, Miyakoshi M, Sato Y, Nakanuma Y. Modulation of the microenvironment by senescent biliary epithelial cells may be involved in the pathogenesis of primary biliary cirrhosis. $J$ Hepatol. 2010;53:318-325.

22. Tsuneyama K, Harada K, Yasoshima M, et al. Monocyte chemotactic protein-1, -2 , and -3 are distinctively expressed in portal tracts and granulomata in primary biliary cirrhosis: implications for pathogenesis. J Pathol. 2001;193:102-109.

23. Lleo A, Invernizzi P, Selmi C, et al. Autophagy: highlighting a novel player in the autoimmunity scenario. J Autoimmunol. 2007; 29:61-68.
24. Sasaki M, Miyakoshi M, Sato Y, Nakanuma Y. Autophagy mediates the process of cellular senescence characterizing bile duct damages in primary biliary cirrhosis. Lab Invest. 2010;90: 835-843.

25. Levine B, Kroemer G. Autophagy in the pathogenesis of disease. Cell. 2008;132:27-42.

26. White E, Lowe SW. Eating to exit: autophagy-enabled senescence revealed. Genes Dev. 2009;23:784-787.

27. Sasaki M, Miyakoshi M, Sato Y, Nakanuma Y. Autophagy may precede cellular senescence of bile ductular cells in ductular reaction in primary biliary cirrhosis. Dig Dis Sci. (Epub ahead of print). doi:10.1007/s10620-011-1929-y.

28. Lleo A, Selmi C, Invernizzi P, et al. Apotopes and the biliary specificity of primary biliary cirrhosis. Hepatology. 2009;49: 871-879.

29. Lleo A, Bowlus CL, Yang GX, et al. Biliary apotopes and antimitochondrial antibodies activate innate immune responses in primary biliary cirrhosis. Hepatology. 2010;52:987-998.

30. Rong G, Zhong R, Lleo A, et al. Epithelial cell specificity and apotope recognition by serum autoantibodies in primary biliary cirrhosis. Hepatology. 2011;54:196-203.

31. Lleo A, Shimoda S, Ishibashi H, Gershwin ME. Primary biliary cirrhosis and autoimmune hepatitis: apotopes and epitopes. J Gastroenterol. 2011;46:29-38. 